\title{
Obesity and Low Back Pain: Is There a Weight of Evidence to Support a Positive Relationship?
}

\author{
Darren M. Roffey • Adele Budiansky • \\ Matthew J. Coyle • Eugene K. Wai
}

Published online: 3 July 2013

(C) Springer Science+Business Media New York 2013

\begin{abstract}
Obesity and low back pain (LBP) are responsible for significant morbidities and financial expenditure. Numerous studies have demonstrated a positive relationship between obesity and LBP, but a concurrent investigation of causality is often omitted. Spinal clinicians routinely prescribe exercise and weight loss for obese patients with LBP, despite a paucity of literature evaluating why obesity might cause LBP or how exercise and weight loss might be suitable treatments for LBP. Etiologies have tended to focus on the biomechanical effects of obesity that lead to excessive loading and degeneration of the lumbar spine. However, recent evidence suggests that systemic inflammation associated with obesity may also be an important
\end{abstract}

D. M. Roffey • E. K. Wai $(\square)$

Clinical Epidemiology Program, Ottawa Hospital Research Institute, 725 Parkdale Avenue, Ottawa, ON, Canada K1Y 4E9

e-mail: ewai@ottawahospital.on.ca

D. M. Roffey

e-mail: droffey@toh.on.ca

D. M. Roffey • A. Budiansky • M. J. Coyle • E. K. Wai

The Ottawa Hospital, University of Ottawa Spine Program, 1053 Carling Avenue, Ottawa, ON, Canada K1Y 4E9

A. Budiansky

e-mail: budianas@mcmaster.ca

M. J. Coyle

e-mail: mcoy1066@uottawa.ca

A. Budiansky

Department of Medicine, Faculty of Health Sciences,

McMaster University, 1280 Main Street West, Hamilton,

ON L8S 4K1, Canada

M. J. Coyle

Faculty of Medicine, University of Ottawa, 451 Smyth Road,

Ottawa, ON, Canada K1H 8M5

\section{E. K. Wai}

Division of Orthopaedic Surgery, Department of Surgery,

University of Ottawa, 451 Smyth Road, Ottawa, ON,

Canada K1H 8M5 contributor to LBP. In this article, the latest evidence investigating the relationship between obesity and LBP is reviewed, an overview of the impact of exercise and weight loss on LBP is provided, and proposed mechanisms connecting obesity, systemic inflammation, and LBP are outlined.

Keywords Obesity · Low back pain · Exercise · Weight loss · Lifestyle modification · Bariatric surgery · Non-surgical . Health care utilization · Body mass index · Inflammation . C-reactive protein $\cdot$ Vitamin C $\cdot$ Morbidity $\cdot$ Etiology

\section{Introduction}

Obesity is one of the most detrimental medical conditions afflicting modern society, not only in terms of morbidity and mortality but also with regards to out-of-pocket, insurance and government costs. As population levels of obesity have continued to rise, so too have the number of individuals with low back pain (LBP). LBP is a common musculoskeletal disorder in both developed and developing countries. Because of the resultant discomfort and disability, LBP is associated with high levels of health care utilization and work absenteeism. Although many suspected risk factors have been studied, the etiology of LBP remains equivocal. Given the increasing number of obese individuals coinciding with the escalating prevalence of LBP, there is a growing interest in establishing the impact of obesity on LBP and determining the physiological causality.

\section{Obesity}

Obesity is defined as abnormal or excessive fat accumulation that presents a risk to health and wellbeing. Originally, obesity was considered the end-product of an imbalanced equation in which the body consumes more calories than it 
burns. Although over-eating and under-exercising are significant contributors, a myriad of genetic, environmental, behavioral, and social factors are now recognized as playing a major role [1,2]. Obesity, categorized at a population level as body mass index (BMI) greater than $30 \mathrm{~kg} / \mathrm{m}^{2}$, is a risk factor for cardiovascular disease and cancer. Fat deposition in the abdominal region has been linked with diabetes. Obesity has also been linked to systemic inflammation which contributes to the pathogenesis of metabolic dysfunction [3].

The latest statistics indicate obesity rates have reached epidemic proportions in North America: $24.1 \%$ of adult Canadians and $35.7 \%$ of adult Americans are currently classified as obese $[4,5]$. The economic impact of obesity and concomitant diseases assume a significant portion of health care expenditure. If current obesity trends continue to escalate, by 2030 all 50 states of the United States of America (USA) could have adult obesity rates of at least $44 \%$ and treatment costs for obesity-related diseases could add $\$ 48$ - $\$ 66$ billion to current estimates of $\$ 147-\$ 210$ billion per year $[6,7]$.

\section{Low Back Pain}

LBP corresponds with spinal and paraspinal symptoms in the lumbosacral region. There are numerous potential sources of LBP including but not limited to intervertebral discs, facet joints, vertebrae, neural structures, muscles, ligaments, and fascia. Often LBP can be difficult to diagnose due to varying presentations, multiple potential etiologies, lack of a definitive diagnostic test, and the complex nature of neuropathic and nociceptive pain [8-10]. As a result, symptoms may become exacerbated, requiring an increase in the complexity and number of treatments.

Around $26 \%$ of North American adults will experience LBP at some point every year [11]; the lifetime prevalence of LBP is estimated at $84 \%$ [12]. With the increasing number of LBP patients has come an exponential rise in the cost of its treatment. Drug prescriptions, in-patient treatments, and emergency services have all been the subject of a significant increase in per-user expenditure [13]. Total direct costs associated with treatment for spine pain (primarily LBP) exceed $\$ 85$ billion per year in the USA [14]. The financial impact would be doubled to almost $\$ 170$ billion per year if disability payments and lost taxation revenue attributable to spinal disorders were also considered [15].

\section{Relationship between Obesity and Low Back Pain}

Obesity has long been suspected as a contributing factor in the presentation of musculoskeletal pain in the hips, knees and feet. Weight accumulation, particularly in the upper body, places a greater mechanical load on weight-bearing joints and structures, potentially increasing the rate of degeneration through excessive wear-and-tear. Patients with increased BMI are more susceptible to distal lower extremity injuries than those within normal bodyweight limits [16]. Based on our experience, spinal clinicians also believe obesity contributes to LBP in much the same manner. Consequently, obese patients are often advised to lose weight upon spinal consultation for two proposed reasons: 1) to decrease the mechanical load on the affected weight-bearing spinal structures and; 2) to moderate the obesity-induced lordotic curvature of the lumbar spine.

Previous reviews and meta-analyses have identified possible connections between obesity and LBP $[17 \cdot, 18]$. Opportunely, a raft of recent studies has added much needed evidence to support a positive relationship between obesity and LBP [19••, 20-23, 24••, 25-33] (Table 1). In addition, results from the Spine Patient Outcomes Research Trial (SPORT) indicate that obesity can influence lumbar spine surgery treatment outcomes. Patients with degenerative spondylolisthesis with BMI greater than $30 \mathrm{~kg} / \mathrm{m}^{2}$ had a higher postoperative infection rate, twice the reoperation rate, and less improvement in physical function at 4-years follow-up than those with BMI less than $30 \mathrm{~kg} / \mathrm{m}^{2}$ [34]. Likewise, obese patients with lumbar disc herniations experienced significantly fewer improvements in primary outcome measures (i.e., physical function, bodily pain, disability) than non-obese patients in both operative and non-operative treatment groups [35•].

The majority of studies to date focus more on establishing a relationship between obesity and LBP rather than examining any physiological causality. Obesity-specific mechanisms that have been mentioned in relation to LBP include: 1) a disproportion of fat versus muscle leading to detrimental compensatory actions; 2) mechanical stressors causing degeneration of load-bearing structures and; 3) chronic wholebody systemic inflammation. High-quality prospective data that supports the general belief of a biomechanical relationship between obesity and LBP is lacking. Moreover, because anecdotal findings and a cohort study [36••] suggest that even mild weight loss results in improvements in LBP, there are likely non-biomechanical pathways involved which have not yet been fully explored.

\section{Bariatric Surgery, Weight Loss, and Low Back Pain}

Obese patients are commonly advised to lose weight to help alleviate their LBP symptomatology. While lifestyle modification provides the foundation for weight loss, bariatric surgery is the only remaining option for some patients due to musculoskeletal difficulties that prevent the completion of daily exercises [37]. Bariatric surgery consistently results in sustained weight loss and decreases in the rate of concomitant diseases and mortality above and beyond that which is possible 

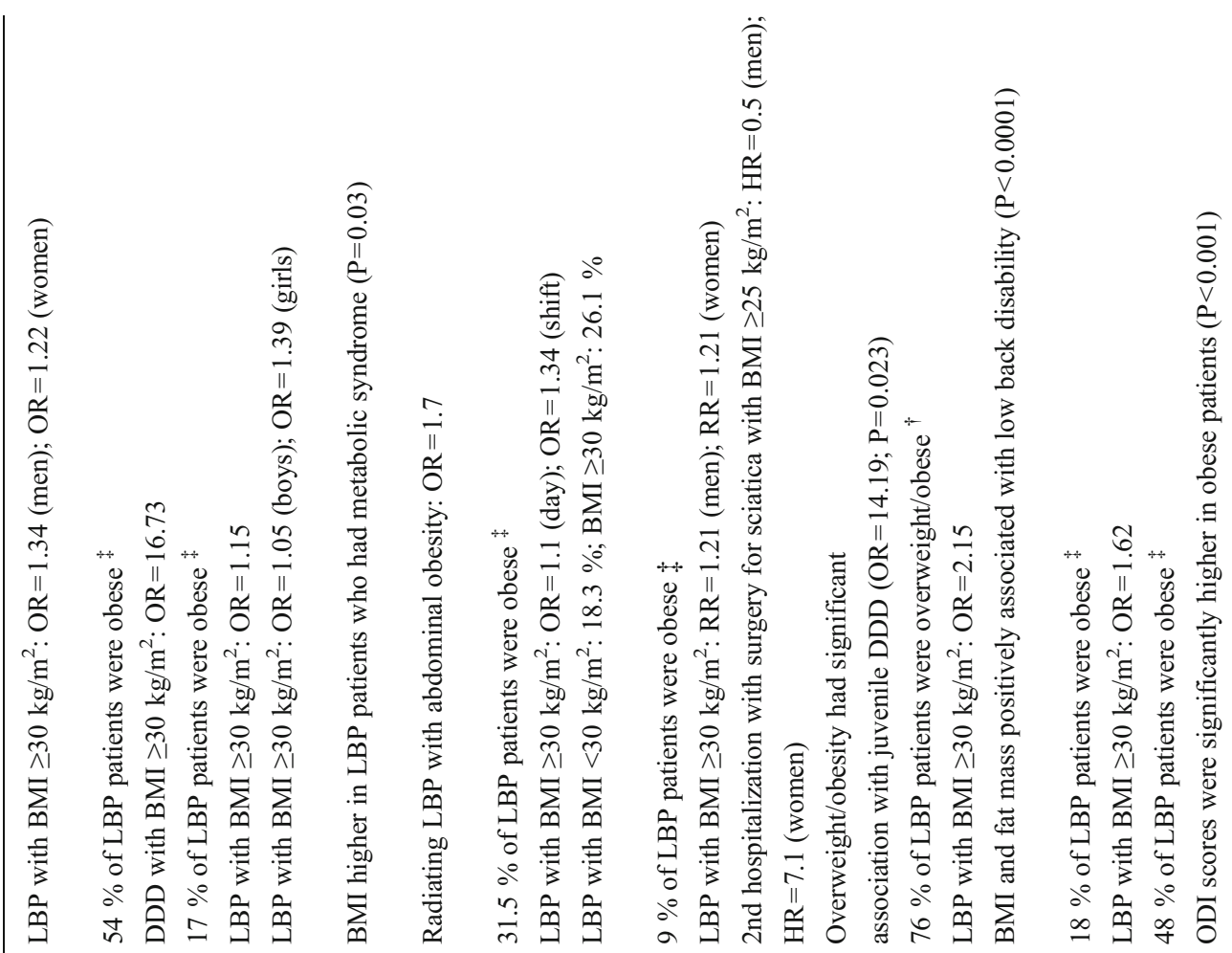

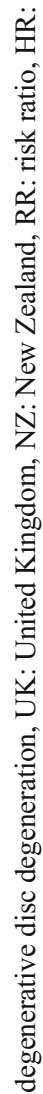

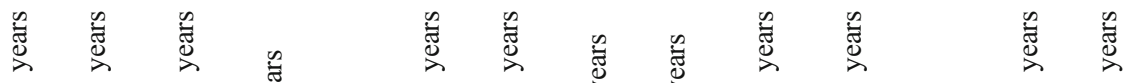
ôे సิ่

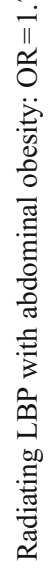

崩

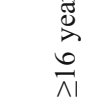

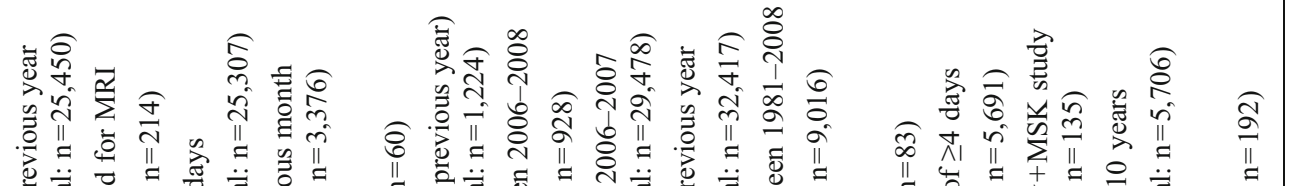

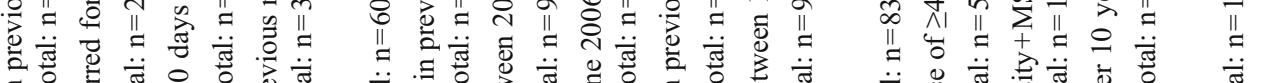

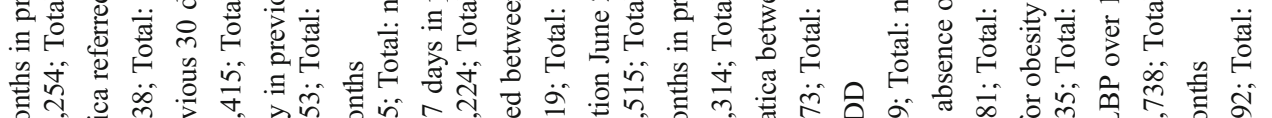

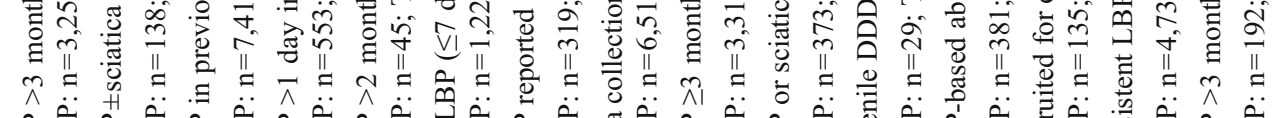

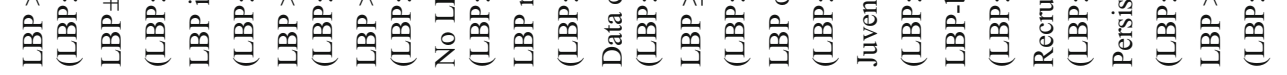

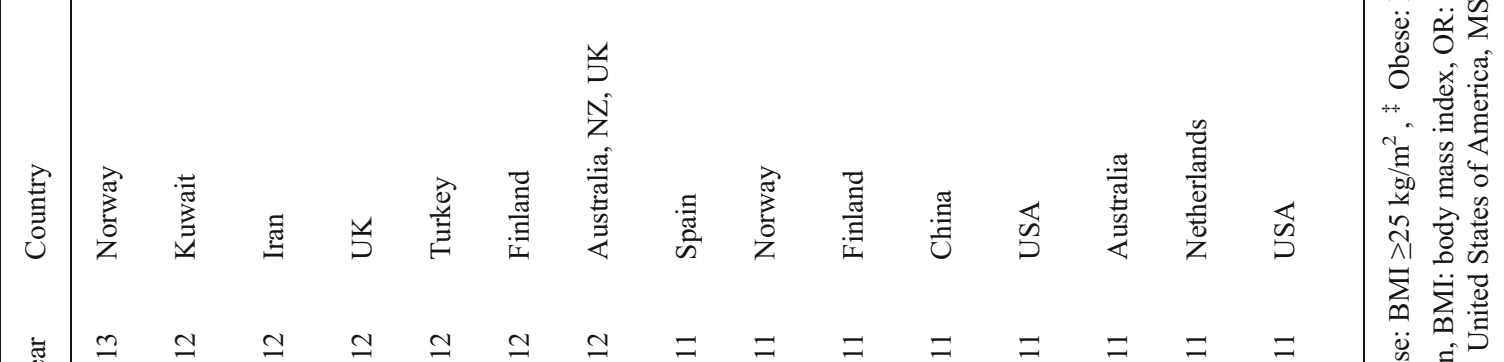

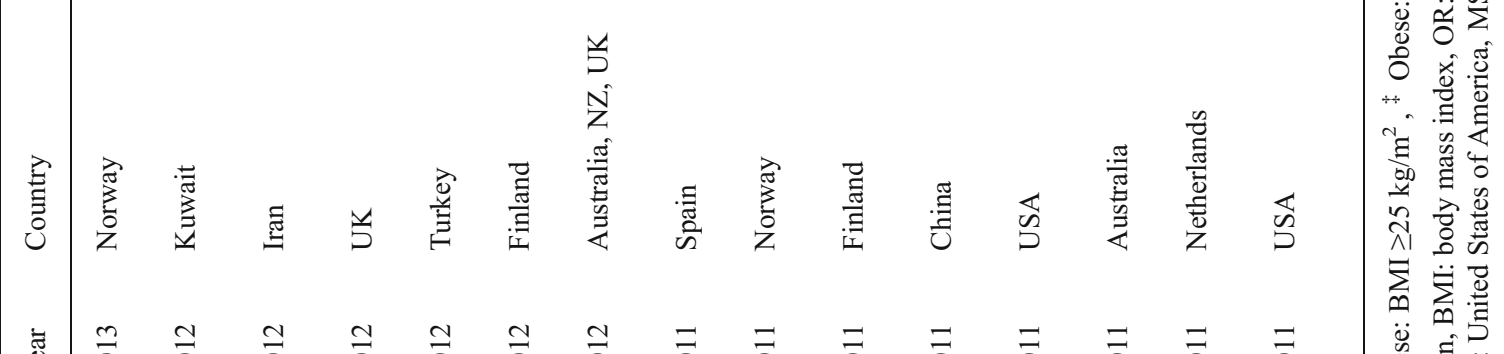

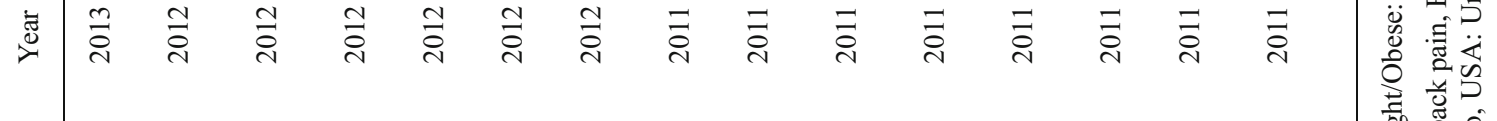

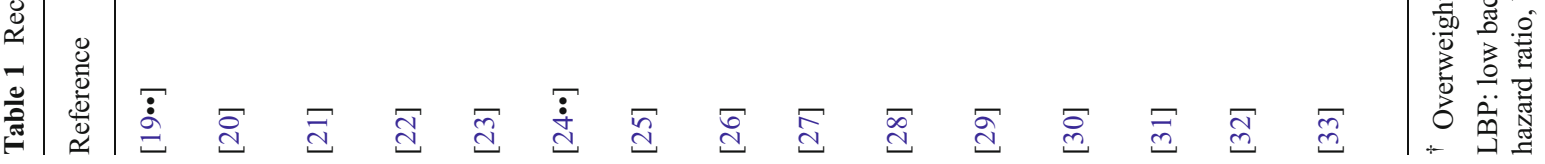


with exercise and dietary changes and pharmacological treatments [38]. As such, indications for bariatric surgery have been relaxed: what was originally considered a procedure for only the morbidly obese (i.e., BMI $\geq 40 \mathrm{~kg} / \mathrm{m}^{2}$, or BMI $\geq 35 \mathrm{~kg} / \mathrm{m}^{2}$ with serious co-existing medical conditions) is now being performed in patients with BMI $30-35 \mathrm{~kg} / \mathrm{m}^{2}$.

Recent studies illustrate the presence of a relationship between weight loss following bariatric surgery and reduced LBP. A prospective cohort study in 30 morbidly obese patients showed that an average reduction in body weight of $37 \mathrm{~kg} 12-$ months after surgery significantly decreased axial and radicular LBP [39]. In a prospective comparative study of 25 patients, an average weight loss of $22 \mathrm{~kg}$ three months after surgery led to a $54 \%$ decrease in the severity of LBP and a significant improvement in quality of life [40 ${ }^{\bullet}$. A similar prospective study in 20 patients indicated that the average weight loss 3-months after surgery was $24 \mathrm{~kg}$, and that the Numeric Pain Rating Scale demonstrated a significant decrease in LBP [41]. Another prospective assessment of 38 patients showed an average decrease in mean weight of $39 \mathrm{~kg}$ at 12 -months post-operation, with a statistically significant mean $44 \%$ decrease in axial LBP on the Visual Analogue Scale [42].

Unfortunately, adverse events and complications have long-been associated with bariatric surgery. Gastric bypass presents the most risk but offers the most benefit, gastric banding has the lowest risk and is the least effective, while sleeve gastrectomy is positioned in-between in terms of morbidity and effectiveness [43]. Of 5364 patients who underwent bariatric surgery, the 1-year mortality rate was $0.06 \%$ and the frequency of complications was $5.4 \%$ for gastric banding, $6.5 \%$ for sleeve gastrectomy, and $9.7 \%$ for gastric bypass [44]. Medical complications tend to focus on malabsorption, gastric dumping syndrome and nutritional deficiencies [45]. In addition, patients undergoing bariatric surgery use more inpatient and non-primary out-patient care during follow-up [46]. Bariatric surgery is clinically-effective and costeffective for obese patients with BMI $30-40 \mathrm{~kg} / \mathrm{m}^{2}$ and diabetes, but is less likely to be cost-effective for patients with BMI $30-35 \mathrm{~kg} / \mathrm{m}^{2}$ and no diabetes [47].

\section{Exercise, Weight Loss, and Low Back Pain}

For the obese patient, completion of a regular exercise regimen (with or without caloric restriction) ideally leads to weight loss and improvements in risk factors for diabetes and cardiovascular disease. Even with negligible weight loss, obese patients with a good level of cardiorespiratory fitness are at reduced risk for cardiovascular mortality compared to lean but unfit individuals [48]. Recent evidence suggests combination exercise (i.e. aerobic +resistance) gives greater benefits for weight loss, fat loss and cardiorespiratory fitness than aerobic or resistance training alone [49]. Regardless of modality, regular exercise is also vitally important for longterm maintenance of weight loss [50]. For these reasons, exercise is a predominant component in lifestyle modifications commonly prescribed by spine clinicians for obese patients suffering from LBP.

Previously, researchers have sought to determine whether low-intensity aerobic exercise, moderate-to-high intensity aerobic exercise, stretching or resistance training programs are better for LBP patients. In 52 sedentary patients with LBP, 6weeks of moderate intensity walking were as effective as 6weeks of muscle strengthening exercises in improving LBP outcomes [51]. Similar improvements in pain intensity, disability, anxiety and depression have been reported in a study of 50 patients with LBP who completed a 12-week high intensity aerobic exercise program compared to a passive modalities group who performed only moderate intensity exercise and general strengthening activities [52]. A comprehensive study of 286 patients with LBP who were randomized to a 12-week program comprising high and low intensity exercise, occupational therapy, and education or a 12-week program comprising back muscle strengthening exercises reported significant improvements in both groups with regard to pain, disability, and most quality of life dimensions over a 24-month follow-up period [53]. An individualized 6-week clinical Pilates program in 60 patients with LBP also produced similar beneficial effects on self-reported disability, pain, function and health-related quality of life as a general exercise program [54].

Currently, the literature is bereft of high-quality studies that elucidate the extent to which exercise and weight loss can reduce LBP for obese patients. Furthermore, although the evidence is clear that exercise is beneficial for LBP, it is not clear which modality of exercise is most suitable. There appears only one pertinent study addressing the interrelationships between exercise, weight loss and LBP. A multidisciplinary prospective cohort study of 46 obese patients with LBP showed that a 12-month medically supervised, non-surgical weight loss program involving meal replacement, caloric restriction, education, exercise, and group therapy could result in significant weight loss and improvements in LBP, disability and function [36••]. This same study also showed a small correlation between weight loss and LBP reduction. Admittedly, whether or not exercise and weight loss were the source of LBP improvements - as opposed to other specific components of the program - remains an open question. Nonetheless, the outcomes of the comprehensive program are promising.

\section{Obesity, Systemic Inflammation, and Low Back Pain}

Studies that investigate the role of obesity in initiating or exacerbating LBP are becoming increasingly prevalent. Recently, associations between obesity and inflammation, inflammation and pain signaling, and LBP and inflammation have 
been postulated. Many pro- and anti-inflammatory mediators that stem from, interact with, and adversely affect adipose tissue and skeletal muscle have been studied in this context. Much of the focus has been placed upon C-reactive protein (CRP), tumor necrosis factor alpha (TNF- $\alpha$ ), interleukin-6 (IL6 ), and adiponectin due to the profusion of evidence and their connection to deleterious musculoskeletal conditions.

Adipose tissue accumulation, particularly in visceral compartments, leads to inflammation through an increase in proinflammatory cytokines and a decrease in anti-inflammatory adipokines [55]. Initiation of the inflammatory process comes from cellular stress at the level of the adipocyte [56]. Adipocytes undergo hyperplasia and hypertrophy, and together with circulating free fatty acids and their by-products, initiate an inflammatory signaling cascade. Inflamed adipocytes recruit circulating monocytes, leading to infiltration of the inflamed adipose tissue and differentiation into local macrophages. Accumulated macrophages contribute to inflammation by releasing pro-inflammatory cytokines. The degree of macrophage infiltration is correlated with the extent of adiposity [57].

CRP, a common marker of inflammation, is consistently found to be elevated in obese patients [58]. BMI and waist circumference are highly correlated to CRP serum levels [59•]. Increased plasma concentrations of CRP are attributable to the pathogenesis of atherosclerosis and diabetes [57, 60]. CRP is mainly produced in the liver in response to various pro-inflammatory cytokines, such as IL-6. Generally thought of as a marker of inflammation, CRP has also been shown to mediate inflammation by up-regulating pro-inflammatory cytokines and down-regulating adiponectin [61].

IL-6 is a cytokine that is released by adipose tissue and in skeletal muscle. IL-6 is primarily modulated by the transcription factor NF-KB, and is positively correlated with levels of obesity [62]. IL-6 has typically been associated with cardiovascular diseases, morbidity, and physical frailty. The idea that IL-6 is a pro-inflammatory cytokine has been perpetuated by the fact that it up-regulates CRP production and is present at high concentrations in the acute inflammatory state [63]. In addition, IL-6 may be involved in initiating a transition from acute inflammation to a chronic inflammatory state [64].

TNF- $\alpha$ is a pro-inflammatory cytokine that is pivotal to inflammation and insulin resistance in obesity. Its release is dependent on increased levels of circulating free fatty acids [65]. TNF- $\alpha$ is released by macrophages that have infiltrated adipose tissue. Specifically, TNF- $\alpha$ is produced as a result of activation of free fatty acid-mediated TLR 4 and NF- $\mathrm{KB}$ in the macrophages [66]. TNF- $\alpha$ also reduces the expression of anti-inflammatory adipokines such as adiponectin [67], whereas adiponectin acts to inhibit NF-KB and TNF- $\alpha$ [68].

Adiponectin is a unique adipokine that exerts its antiinflammatory effects in adipose tissue, in macrophages, and in skeletal muscle. Circulating adiponectin levels decrease with obesity and are present in higher concentrations in lean subjects [69]. Low levels of adiponectin are associated with increased morbidity and high levels of CRP and IL-6 [70].

In the obese state, macrophages accumulate in skeletal muscle. Macrophages and lipids that accumulate in skeletal muscle can cause the release of pro-inflammatory cytokines, which then contribute to systemic inflammation. There is evidence that pro-inflammatory cytokines released in skeletal muscle can lead to peripheral insulin resistance and impaired glucose control [71], which can then further exacerbate inflammation and lead to hyperalgesia $[72,73]$.

Noxious or even normally benign stimuli acting in inflamed tissue can cause or amplify pain due to decreased neural excitation thresholds [74]. It appears that pro- and anti-inflammatory cytokines play an important role in this pain modulation. Obese Zucker rats were shown to have an increased sensitivity to pain, while expression of adiponectin receptor mRNA and upregulated TNF- $\alpha$ mRNA were also identified in their spinal cords [75]. Other studies have further demonstrated that TNF- $\alpha$ and IL- 6 are involved in pain signaling and hyperalgesia $[76,77]$.

Given these findings, LBP may be mediated or exacerbated by alterations to pain modulation through systemic inflammation. Previous studies have indicated elevated inflammatory mediators are found in herniated lumbar discs [78] and vertebral end-plate changes [79]. Only one study though has examined the interrelations among obesity, systemic inflammation, and LBP. Analysis of a populationbased sample $(n=15,322)$ drawn from the 1999 to 2004 National Health and Nutrition Examination Survey found that normal weight participants with elevated CRP had 1.74 greater odds of reporting LBP than participants with non-elevated CRP, while obese participants with elevated CRP had 2.87 greater odds of reporting LBP than obese participants with non-elevated CRP [80••]. This study also showed that participants with a greater waist circumference were more likely to report LBP. Given these findings, further investigation is warranted into effective treatment methodologies and modalities to negate the impact of systemic inflammation on LBP in obese patients.

\section{Exercise, Weight Loss, Decreased Systemic Inflammation and Reduced LBP}

Since obesity and LBP both have an association with systemic inflammation, the question arises as to whether a specific intervention exists that can potentially alleviate both chronic conditions simultaneously. The proposition put forward in this review is that exercise and weight loss can improve LBP in obese patients, in part, through the beneficial effects that regular exercise and reduced adiposity have on the systemic inflammatory state associated with obesity. 
Exercise and weight loss can lead to decreased subcutaneous adipose tissue, and more importantly in the context of inflammation, decreased visceral adiposity. This is thought to occur via a decrease in adipocyte size, although the number of adipocytes in adipose tissue may also be altered [81]. Exercise programs that invoke weight loss have also been shown to reduce macrophage infiltration in adipose tissue [82]. Together, these changes within adipose tissue decrease expression of pro-inflammatory mediators and markers while increasing the expression of anti-inflammatory adipokines.

Exercise positively alters the level of pro- and antiinflammatory mediators and markers in obese [83*0] and sedentary [84] individuals, with those who engage in exercise generally having lower levels of CRP [85]. Weight loss can result in decreased CRP; larger reductions in weight can affect CRP levels more markedly [86]. Programs combining aerobic exercise, resistance training and weight loss have been particularly effective in down-regulating CRP [83••, 87]. Specifically, CRP was correlated with both aerobic capacity and weight loss independently [87]. In contrast, some exercise interventions without significant weight loss have shown that circulating CRP levels were not affected [88].

Studies examining the effect of exercise and weight loss on TNF- $\alpha$ have produced ambiguous results. TNF- $\alpha$ levels can be markedly reduced after a program of exercise and weight loss $[70,83 \bullet \cdot, 89]$. However, some studies have indicated that weight loss alone can decrease TNF- $\alpha$ [90, 91], while others have shown that exercise and not weight loss can decrease TNF- $\alpha$ expression [92].

The effect of exercise on IL-6 is controversial because IL6 may have pro- or anti-inflammatory functions depending on the target tissue and stimuli involved. Exercise studies have produced conflicting results because IL- 6 increases during acute exercise [93], but decreases with regular exercise [70]. Weight loss effects on IL-6 have not produced clear results [94].

As with the pro-inflammatory cytokines and markers, studies of adiponectin, exercise, and weight loss in obese patients have produced variable results. Aerobic and resistance training produced more consistent increases in adiponectin if these programs also resulted in significant fat loss [69]. One study demonstrated that exercise with or without diet-induced weight loss increased adiponectin receptor expression, but only diet-induced weight loss produced an actual increase in serum adiponectin levels [95].

Regular exercise can improve local and systemic inflammation by reducing intramuscular adipose content in skeletal muscles [96•]. Additional benefits include glucose uptake, increased insulin sensitivity and down regulation of proinflammatory cytokine receptors [92]. Enhanced glucose control is relevant to improved pain modulation because hyperglycemia and insulin resistance have been shown to contribute to systemic inflammation [55] and hyperalgesia [73].
By reducing the degree of inflammation through exercise and weight loss, obese patients can potentially control the progression of their LBP. Despite the presence of conflicting studies about the importance of weight loss in comparison to exercise interventions, and whether a combination of the two is necessary in order to obtain an anti-inflammatory effect, there is sufficient evidence such that a simplified model has been put together to propose that exercise and weight loss can relieve LBP through changes to the pro-inflammatory environment (Fig. 1). Specifically, reduction in adipose tissue volume and conditioning of skeletal muscle can ultimately reduce the level of circulating pain mediating cytokines (i.e., Il- 6 and TNF- $\alpha$ ) and markers of inflammation (i.e., CRP), and increase the level of circulating anti-inflammatory adipokines (i.e., adiponectin)]. This reduction in systemic inflammation can subsequently decrease the extent of inflammatory insult on neurons and improve pain thresholds and pain modulation, therefore allowing for a more appropriate response to mechanical strain or benign stimuli.

\section{Future Concepts and Theories to Explore}

The presence of pain can negatively affect the success of weight loss programs [97]. In addition, interventional studies are often hampered by the non-specific nature of LBP. Given the multiple potential etiologies of LBP, there is likely significant variability in individual responses to any targeted treatments, reducing the power of any study and ultimately lessening the effectiveness of the treatment if applied too

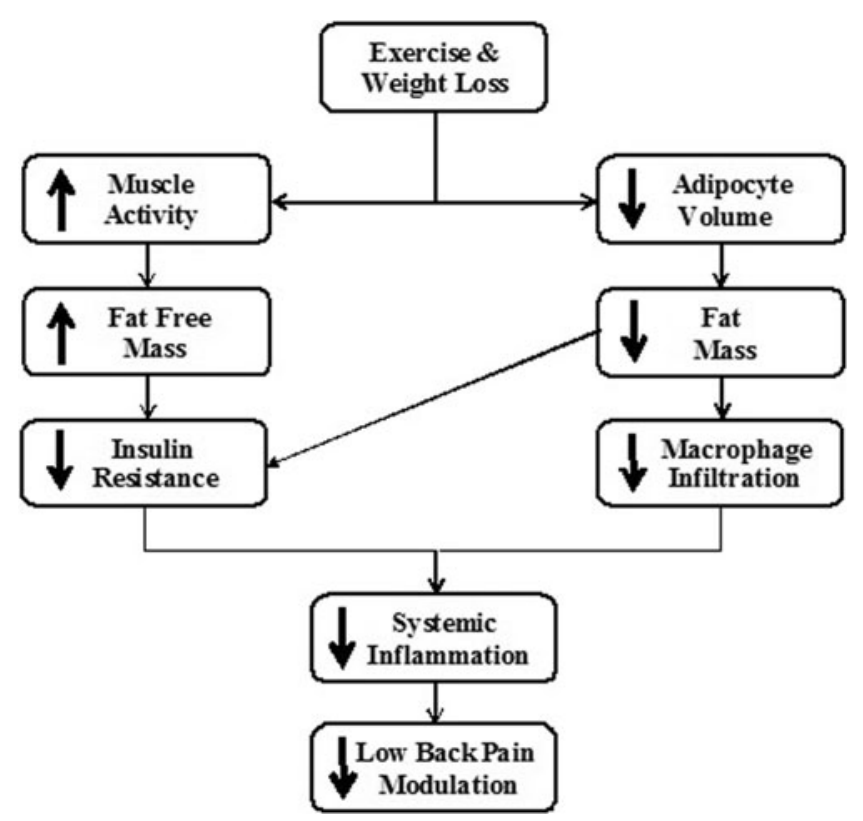

Fig. 1 A simplified model proposing how exercise and weight loss might reduce low back pain through physiological changes to the proinflammatory environment 
broadly. Hence, the ability to accurately identify the cause of the LBP would greatly improve the chance of success for any future applications of treatment. A recent study suggests that an interrelationship might exist between obesity, inflammation, and LBP [80••]. In this review, the theory put forward is that obesity causes increased systemic inflammation, increased inflammation might contribute to increased LBP, and that exercise and weight loss may lead to decreased inflammation and reduced LBP. Looking further into the concept of obesity, inflammation and LBP has significant merit because trying to reduce inflammatory levels in obese individuals with LBP may be the link in the cycle between their pain and obesity. As discussed, one potential treatment plan to reduce systematic inflammation and LBP in obese patients is through the prescription of aerobic exercise (e.g., walking) or combination exercise (i.e., aerobic + resistance) and weight loss. Another method could be through pharmacological manipulation, such as vitamin-C supplementation. To date, research on inflammation and vitamin-C supplementation in obese individuals has been sparse [98, 99], and only one study has outlined a theory connecting vitamin-C and degenerative spinal conditions [100].

\section{Conclusion}

It is without question that obesity and LBP are responsible for numerous comorbidities that pose a significant challenge to health care systems worldwide. The literature suggests a positive relationship exists between obesity and LBP. However, there is a shortage of studies discussing the possible pathways in which obesity leads to LBP, or whether interventions that include exercise and weight loss are a viable treatment for LBP. Given the complexities of these medical conditions, and the myriad of possible mechanisms involved, some spinal clinicians postulate that this relationship may be purely coincidental. Recent evidence suggests that systemic inflammation associated with obesity may provide a link with LBP. Despite the clinical equipoise, it is a promising area in which to identify a cohort of patients that would benefit from exercise-based weight loss interventions to address this theory. Overall, despite the current lack of evidence in regards to exercise, weight loss and reduction in LBP in obese patients, it is important to remember that regular exercise and weight loss is of benefit to other aspects of health and well-being aside from a potential reduction in LBP.

\section{Compliance with Ethics Guidelines}

Conflict of Interest Darren M. Roffey is a consultant for Palladian Health.

Adele Budiansky declares that she has no conflict of interest.

Matthew J. Coyle declares that he has no conflict of interest.

Eugene K. Wai declares that he has no conflict of interest.
Human and Animal Rights and Informed Consent This article does not contain any studies with human or animal subjects performed by any of the authors.

\section{References}

Papers of particular interest, published recently, have been highlighted as:

- Of importance

•- Of major importance

1. Heitmann BL, Westerterp KR, Loos RJ, et al. Obesity: lessons from evolution and the environment. Obes Rev. 2012;13:910-22.

2. Moore CJ, Cunningham SA. Social position, psychological stress, and obesity: a systematic review. J Acad Nutr Diet. 2012;112:518 26.

3. Scarpellini E, Tack J. Obesity and metabolic syndrome: an inflammatory condition. Dig Dis. 2012;30:148-53.

4. Shields M, Carroll MD, Ogden CL. Adult obesity prevalence in Canada and the United States. NCHS Data Brief. 2011;56:1-8.

5. Ogden CL, Carroll MD, Kit BK, Flegal KM. Prevalence of obesity in the United States, 2009-2010. NCHS Data Brief. 2012;82:1-8.

6. Finkelstein EA, Khavjou OA, Thompson H, et al. Obesity and severe obesity forecasts through 2030. Am J Prev Med. 2012;42:563-70.

7. Voelker R. Escalating obesity rates pose health, budget threats. JAMA. 2012;308:1514.

8. Manusov EG. Evaluation and diagnosis of low back pain. Prim Care. 2012;39:471-9.

9. Carragee EJ, Tanner CM, Khurana S, et al. The rates of falsepositive lumbar discography in select patients without low back symptoms. Spine (Phila Pa 1976). 2000;25:1373-80.

10. Jensen MC, Brant-Zawadzki MN, Obuchowski N, et al. Magnetic resonance imaging of the lumbar spine in people without back pain. N Engl J Med. 1994;331:69-73.

11. Deyo RA, Mirza SK, Martin BI. Back pain prevalence and visit rates: estimates from U.S. national surveys. Spine (Phila Pa 1976). 2006;31:2724-7.

12. Cassidy JD, Carroll LJ, Cote P. The Saskatchewan health and back pain survey. The prevalence of low back pain and related disability in Saskatchewan adults. Spine (Phila Pa 1976). 1998;23:1860-6.

13. Martin BI, Turner JA, Mirza SK, et al. Trends in health care expenditures, utilization, and health status among US adults with spine problems, 1997-2006. Spine (Phila Pa 1976). 2009;34(19):2077-84.

14. Martin BI, Deyo RA, Mirza SK, et al. Expenditures and health status among adults with back and neck problems. JAMA. 2008;299:656-64.

15. Dagenais S, Haldeman S. Commentary: laboring to understand the economic impact of spinal disorders. Spine J. 2012;12:111921.

16. Sabharwal S, Root MZ. Impact of obesity on orthopaedics. J Bone Joint Surg Am. 2012;94:1045-52.

17. - Shiri R, Karppinen J, Leino-Arjas P, et al. The association between obesity and low back pain: a meta-analysis. Am J Epidemiol. 2010;171:135-54. This meta-analysis found that obesity was associated with increased incidence of low back pain for $\geq 1$ day in the past 12 months.

18. Shiri R, Karppinen J, Leino-Arjas P, et al. Cardiovascular and lifestyle risk factors in lumbar radicular pain or clinically defined sciatica: a systematic review. Eur Spine J. 2007;16:2043-54.

19. •• Heuch I, Heuch I, Hagen K, Zwart JA. Body mass index as a risk factor for developing chronic low back pain: a follow-up in 
the Nord-Trøndelag Health Study. Spine. 2013;38(2):133-9. This prospective cohort study indicated that high body mass index values may predispose to chronic low back pain 11 years later, both in individuals with and without LBP at baseline.

20. Al-Saeed O, Al-Jarallah K, Raeess M, et al. Magnetic resonance imaging of the lumbar spine in young arabs with low back pain. Asian Spine J. 2012;64:249-56.

21. Biglarian A, Seifi B, Bakhshi E, et al. Low back pain prevalence and associated factors in Iranian population: findings from the national health survey. Pain Res Treat. 2012;653060:1-5.

22. Deere KC, Clinch J, Holliday K, et al. Obesity is a risk factor for musculoskeletal pain in adolescents: findings from a populationbased cohort. Pain. 2012;153:1932-8.

23. Duruoz MT, Turan Y, Gurgan A, Deveci H. Evaluation of metabolic syndrome in patients with chronic low back pain. Rheumatol Int. 2012;32:663-7.

24. • Shiri R, Solovieva S, Husgafvel-Pursiainen K, et al. The role of obesity and physical activity in non-specific and radiating low back pain: The Young Finns study. Semin Arthritis Rheum. 2012. doi:10.1016/j.semarthrit.2012.09.002. This prospective cohort study showed that both obesity and low level of physical activity are independent risk factors of radiating low back pain, and that obese individuals should stay physically active, even if they may not lose weight.

25. Zhao I, Bogossian F, Turner C. The effects of shift work and interaction between shift work and overweight/obesity on low back pain in nurses: results from a longitudinal study. J Occup Environ Med. 2012;54:820-5.

26. Fernandez-de-las-Penas C, Hernandez-Barrera V, Alonso-Blanco $\mathrm{C}$, et al. Prevalence of neck and low back pain in communitydwelling adults in Spain: a population-based national study. Spine (Phila Pa 1976). 2011;36:E213-9.

27. Nilsen TI, Holtermann A, Mork PJ. Physical exercise, body mass index, and risk of chronic pain in the low back and neck/shoulders: longitudinal data from the Nord-Trondelag Health Study. Am J Epidemiol. 2011;174:267-73.

28. Rivinoja AE, Paananen MV, Taimela SP, et al. Sports, smoking, and overweight during adolescence as predictors of sciatica in adulthood: a 28-year follow-up study of a birth cohort. Am J Epidemiol. 2011;173:890-7.

29. Samartzis D, Karppinen J, Mok F. A population-based study of juvenile disc degeneration and its association with overweight and obesity, low back pain, and diminished functional status. J Bone Joint Surg Am. 2011;93:662-70.

30. Tsai SP, Bhojani FA, Wendt JK. Risk factors for illness absence due to musculoskeletal disorders in a 4-year prospective study of a petroleum-manufacturing population. J Occup Environ Med. 2011;53:434-40

31. Urquhart DM, Berry P, Wluka AE, et al. 2011 Young Investigator Award winner: Increased fat mass is associated with high levels of low back pain intensity and disability. Spine (Phila Pa 1976). 2011;36:1320-5

32. van Oostrom SH, Monique Verschuren WM, de Vet HC, Picavet HS. Ten year course of low back pain in an adult population-based cohort-the Doetinchem cohort study. Eur J Pain. 2011;15:993-8.

33. Vincent HK, Omli MR, Day T, et al. Fear of movement, quality of life, and self-reported disability in obese patients with chronic lumbar pain. Pain Med. 2011;121:154-64.

34. Rihn JA, Radcliff K, Hilibrand AS, et al. Does obesity affect outcomes of treatment for lumbar stenosis and degenerative spondylolisthesis? Analysis of the Spine Patient Outcomes Research Trial SPORT. Spine (Phila Pa 1976). 2012;37:1933-46.

35. • Rihn JA, Kurd M, Hilibrand AS, et al. The influence of obesity on the outcome of treatment of lumbar disc herniation: analysis of the Spine Patient Outcomes Research Trial SPORT. J Bone Joint Surg Am. 2013;95:1-8. This prospective cohort study that after four years, obese patients realized less clinical benefit from both operative and nonoperative treatment of lumbar disc herniation compared to non-obese patients.

36. $\bullet$ Roffey DM, Ashdown LC, Dornan HD, et al. Pilot evaluation of a multidisciplinary, medically supervised, nonsurgical weight loss program on the severity of low back pain in obese adults. Spine J. 2011;11:197-204. This prospective cohort pilot study demonstrated that a combination of meal replacement, caloric restriction, education, exercise, and group therapy was successful at reducing the severity of $L B P$ and decreasing the burden of disability in 46 morbidly obese adults.

37. Ritter S, Vetter ML, Sarwer DB. Lifestyle modifications and surgical options in the treatment of patients with obesity and type 2 diabetes mellitus. Postgrad Med. 2012;124:168-80.

38. Lundell L. Principles and results of bariatric surgery. Dig Dis. 2012;30:173-7.

39. Lidar Z, Behrbalk E, Regev GJ, et al. Intervertebral disc height changes after weight reduction in morbidly obese patients and its effect on quality of life and radicular and low back pain. Spine (Phila Pa 1976). 2012;37:1947-52.

40. - Vincent HK, Ben-David K, Conrad BP, et al. Rapid changes in gait, musculoskeletal pain, and quality of life after bariatric surgery. Surg Obes Relat Dis. 2012;8:346-54. This prospective comparative study showed that at 3-months follow-up, bariatric surgery had resulted in weight loss of $21.6 \mathrm{~kg}$ and a decrease in the severity of low back pain by $54 \%$.

41. Josbeno DA, Jakicic JM, Hergenroeder A, Eid GM. Physical activity and physical function changes in obese individuals after gastric bypass surgery. Surg Obes Relat Dis. 2010;6:361-6.

42. Khoueir P, Black MH, Crookes PF, et al. Prospective assessment of axial back pain symptoms before and after bariatric weight reduction surgery. Spine J. 2009;9:454-63.

43. Jackson TD, Hutter MM. Morbidity and effectiveness of laparoscopic sleeve gastrectomy, adjustable gastric band, and gastric bypass for morbid obesity. Adv Surg. 2012;46:255-68.

44. Chebli JE, Schindler R. The results of a surgical complication protection program BLIS, Inc. for private pay bariatric patients in the U.S.: 2006-2011. Obes Surg. 2012;22:1798-801.

45. Hammer HF. Medical complications of bariatric surgery: focus on malabsorption and dumping syndrome. Dig Dis. 2012;30:182-6.

46. Neovius M, Narbro K, Keating C, et al. Health care use during 20 years following bariatric surgery. JAMA. 2012;308:1132-41.

47. Picot J, Jones J, Colquitt JL, et al. Weight loss surgery for mild to moderate obesity: a systematic review and economic evaluation. Obes Surg. 2012;22:1496-506.

48. Poirier P, Despres JP. Exercise in weight management of obesity. Cardiol Clin. 2001;19:459-70.

49. Ho SS, Dhaliwal SS, Hills AP, Pal S. The effect of 12 weeks of aerobic, resistance or combination exercise training on cardiovascular risk factors in the overweight and obese in a randomized trial. BMC Publ Health. 2012;12:704.

50. Ogden LG, Stroebele N, Wyatt HR, et al. Cluster analysis of the national weight control registry to identify distinct subgroups maintaining successful weight loss. Obesity Silver Spring. 2012;20:2039-47.

51. Shnayderman I, Katz-Leurer M. An aerobic walking programme versus muscle strengthening programme for chronic low back pain: a randomized controlled trial. Clin Rehabil. 2013;27(3):207-14.

52. Murtezani A, Hundozi H, Orovcanec N, et al. A comparison of high intensity aerobic exercise and passive modalities for the treatment of workers with chronic low back pain: a randomized, controlled trial. Eur J Phys Rehabil Med. 2011;47:359-66.

53. Dufour N, Thamsborg G, Oefeldt A, et al. Treatment of chronic low back pain: a randomized, clinical trial comparing group-based multidisciplinary biopsychosocial rehabilitation and intensive 
individual therapist-assisted back muscle strengthening exercises. Spine (Phila Pa 1976). 2010;35:469-76.

54. Wajswelner H, Metcalf B, Bennell K. Clinical pilates versus general exercise for chronic low back pain: randomized trial. Med Sci Sports Exerc. 2012;44:1197-205.

55. Piya MK, McTernan PG, Kumar S. Adipokine inflammation and insulin resistance: the role of glucose, lipids and endotoxin. J Endocrinol. 2013;216:T1-T15.

56. Enos RT, Davis JM, Velazquez KT, et al. Influence of dietary saturated fat content on adiposity, macrophage behavior, inflammation, and metabolism: composition matters. J Lipid Res. 2013;54:152-63.

57. Wieser V, Moschen AR, Tilg H. Inflammation, cytokines and insulin resistance: a clinical perspective. Arch Immunol Ther Exp (Warsz). 2013;61(2):119-25.

58. Zavala G, Long KZ, Garcia OP, Caamaño MD, Aguilar T, Salgado $\mathrm{LM}$, et al. Specific micronutrient concentrations are associated with inflammatory cytokines in a rural population of Mexican women with a high prevalence of obesity. Br J Nutr. 2012;29:1-9.

59. - Choi J, Joseph L, Pilote L. Obesity and C-reactive protein in various populations: a systematic review and meta-analysis. Obes Rev. 2013;14(3):232-44. This review found that obesity was associated with elevated levels of $C$-reactive protein, and that the association is stronger in women and North Americans/ Europeans.

60. Laframboise WA, Dhir R, Kelly LA, et al. Serum protein profiles predict coronary artery disease in symptomatic patients referred for coronary angiography. BMC Med. 2012;10:157.

61. Kaneko H, Anzai T, Nagai T, et al. Human C-reactive protein exacerbates metabolic disorders in association with adipose tissue remodelling. Cardiovasc Res. 2011;91:546-55.

62. Lira FS, Rosa JC, Dos Santos RV, et al. Visceral fat decreased by long-term interdisciplinary lifestyle therapy correlated positively with interleukin- 6 and tumor necrosis factor-alpha and negatively with adiponectin levels in obese adolescents. Metabolism. 2011;60:359-65.

63. Lee DE, Kehlenbrink S, Lee H, et al. Getting the message across: mechanisms of physiological cross talk by adipose tissue. Am J Physiol Endocrinol Metab. 2009;296:E1210-29.

64. Ferraccioli G, Bracci-Laudiero L, Alivernini S, et al. Interleukin1 beta and interleukin- 6 in arthritis animal models: roles in the early phase of transition from acute to chronic inflammation and relevance for human rheumatoid arthritis. Mol Med. 2010;16:552-7.

65. Cave MC, Hurt RT, Frazier TH, et al. Obesity, inflammation, and the potential application of pharmaconutrition. Nutr Clin Pract. 2008;23:16-34.

66. Shi H, Kokoeva MV, Inouye K, et al. TLR4 links innate immunity and fatty acid-induced insulin resistance. J Clin Invest. 2006; 116:3015-25.

67. Bruun JM, Lihn AS, Verdich C, et al. Regulation of adiponectin by adipose tissue-derived cytokines: in vivo and in vitro investigations in humans. Am J Physiol Endocrinol Metab. 2003;285:E527-33.

68. Ouchi N, Kihara S, Arita Y, et al. Adiponectin, an adipocytederived plasma protein, inhibits endothelial NF-kappaB signaling through a cAMP-dependent pathway. Circulation. 2000; 102:1296-301.

69. Puglisi MJ, Fernandez ML. Modulation of C-reactive protein, tumor necrosis factor-alpha, and adiponectin by diet, exercise, and weight loss. J Nutr. 2008;138:2293-6.

70. Bruun JM, Helge JW, Richelsen B, Stallknecht B. Diet and exercise reduce low-grade inflammation and macrophage infiltration in adipose tissue but not in skeletal muscle in severely obese subjects. Am J Physiol Endocrinol Metab. 2006;290:E961-7.

71. Olefsky JM, Glass CK. Macrophages, inflammation, and insulin resistance. Annu Rev Physiol. 2010;72:219-46.
72. Devaraj S, Venugopal SK, Singh U, Jialal I. Hyperglycemia induces monocytic release of interleukin- 6 via induction of protein kinase c-alpha and -beta. Diabetes. 2005;54:85-91.

73. Romanovsky D, Cruz NF, Dienel GA, Dobretsov M. Mechanical hyperalgesia correlates with insulin deficiency in normoglycemic streptozotocin-treated rats. Neurobiol Dis. 2006;24:384-94.

74. Kidd BL, Urban LA. Mechanisms of inflammatory pain. Br J Anaesth. 2001;87:3-11.

75. Iannitti T, Graham A, Dolan S. Increased central and peripheral inflammation and inflammatory hyperalgesia in Zucker rat model of leptin receptor deficiency and genetic obesity. Exp Physiol. 2012;97:1236-45.

76. Zhang L, Berta T, Xu ZZ, et al. TNF-alpha contributes to spinal cord synaptic plasticity and inflammatory pain: distinct role of TNF receptor subtypes 1 and 2. Pain. 2011;152:419-27.

77. Manjavachi MN, Motta EM, Marotta DM, et al. Mechanisms involved in IL-6-induced muscular mechanical hyperalgesia in mice. Pain. 2010;151:345-55.

78. Burke JG, Watson RW, McCormack D, et al. Intervertebral discs which cause low back pain secrete high levels of proinflammatory mediators. J Bone Joint Surg Br. 2002;84:196-201.

79. Rannou F, Ouanes W, Boutron I, et al. High-sensitivity C-reactive protein in chronic low back pain with vertebral end-plate Modic signal changes. Arthritis Rheum. 2007;57:1311-5.

80. • Briggs MS, Givens DL, Schmitt LC, Taylor CA. The relationships of C-reactive protein and obesity to the prevalence and the odds of reporting low back pain. Arch Phys Med Rehabil. 2013;94(4):745-52. This cross-sectional analysis is the first of its kind to show that high levels of C-reactive protein may increase the odds of reporting low back pain in obese patients, and that patients with high waist circumference values had significantly greater odds of reportinglow back pain.

81. Thompson D, Karpe F, Lafontan M, Frayn K. Physical activity and exercise in the regulation of human adipose tissue physiology. Physiol Rev. 2012;92:157-91.

82. Kawanishi N, Yano H, Yokogawa Y, Suzuki K. Exercise training inhibits inflammation in adipose tissue via both suppression of macrophage infiltration and acceleration of phenotypic switching from M1 to M2 macrophages in high-fat-diet-induced obese mice. Exerc Immunol Rev. 2010;16:105-18.

83. • Ho SS, Dhaliwal SS, Hills AP, Pal S. Effects of chronic exercise training on inflammatory markers in Australian overweight and obese individuals in a randomized controlled trial. Inflammation. 2013:36(6):625-32. This trial demonstrated that 12-weeks of moderate-intensity aerobic, resistance, but mainly combination exercise training decreased inflammatory markers in obese individuals compared to no exercise.

84. Bergstrom G, Behre CJ, Schmidt C. Moderate intensities of leisure-time physical activity are associated with lower levels of high-sensitivity C-reactive protein in healthy middle-aged men. Angiology. 2012;63:412-5.

85. McFarlin BK, Flynn MG, Campbell WW, et al. Physical activity status, but not age, influences inflammatory biomarkers and tolllike receptor 4. J Gerontol A Biol Sci Med Sci. 2006;61:388-93.

86. Selvin E, Paynter NP, Erlinger TP. The effect of weight loss on Creactive protein: a systematic review. Arch Intern Med. 2007;167:31-9.

87. Jae SY, Fernhall B, Heffernan KS, et al. Effects of lifestyle modifications on $\mathrm{C}$-reactive protein: contribution of weight loss and improved aerobic capacity. Metabolism. 2006;55:825-31.

88. Campbell KL, Campbell PT, Ulrich CM, et al. No reduction in Creactive protein following a 12 -month randomized controlled trial of exercise in men and women. Cancer Epidemiol Biomarkers Prev. 2008; 17:1714-8.

89. Ahmadi N, Eshaghian S, Huizenga R, et al. Effects of intense exercise and moderate caloric restriction on cardiovascular risk factors and inflammation. Am J Med. 2011;124:978-82. 
90. Sharman MJ, Volek JS. Weight loss leads to reductions in inflammatory biomarkers after a very-low-carbohydrate diet and a lowfat diet in overweight men. Clin Sci Lond. 2004;107:365-9.

91. Ferrier KE, Nestel P, Taylor A, et al. Diet but not aerobic exercise training reduces skeletal muscle TNF-alpha in overweight humans. Diabetologia. 2004;47:630-7.

92. Lambert CP, Wright NR, Finck BN, Villareal DT. Exercise but not diet-induced weight loss decreases skeletal muscle inflammatory gene expression in frail obese elderly persons. J Appl Physiol. 2008;105:473-8.

93. Petersen AM, Pedersen BK. The anti-inflammatory effect of exercise. J Appl Physiol. 2005;98:1154-62.

94. Oberhauser F, Schulte DM, Faust M, et al. Weight loss due to a very low calorie diet differentially affects insulin sensitivity and interleukin-6 serum levels in nondiabetic obese human subjects. Horm Metab Res. 2012;44:465-70.

95. Christiansen T, Paulsen SK, Bruun JM, et al. Diet-induced weight loss and exercise alone and in combination enhance the expression of adiponectin receptors in adipose tissue and skeletal muscle, but only diet-induced weight loss enhanced circulating adiponectin. J Clin Endocrinol Metab. 2010;95:911-9.
96. - Murphy JC, McDaniel JL, Mora K, et al. Preferential reductions in intermuscular and visceral adipose tissue with exercise-induced weight loss compared with calorie restriction. J Appl Physiol. 2012;112:79-85. This trial showed that 12-months of calorie restriction or exercise-induced weight loss both decreased intermuscular adipose tissue and visceral adipose tissue volumes, but only exercise appears to result in preferential reductions in both fat depots.

97. Wachholtz A, Binks M, Eisenson H, et al. Does pain predict interference with daily functioning and weight loss in an obese residential treatment-seeking population? Int J Behav Med. 2010;17:118-24.

98. Mah E, Matos MD, Kawiecki D, et al. Vitamin C status is related to proinflammatory responses and impaired vascular endothelial function in healthy, college-aged lean and obese men. J Am Diet Assoc. 2011;111:737-43.

99. Calder PC, Ahluwalia N, Brouns F, et al. Dietary factors and lowgrade inflammation in relation to overweight and obesity. $\mathrm{Br} \mathrm{J}$ Nutr. 2011;1063:S5-S78.

100. Smith VH. Vitamin C deficiency is an under-diagnosed contributor to degenerative disc disease in the elderly. Med Hypotheses. 2010;74:695-7. 